\title{
Successful delayed-interval delivery performed 128 days after the vaginal delivery of the first fetus in a twin pregnancy
}

\author{
Yu-Jin Koo \\ Department of Obstetrics and Gynecology, Yeungnam University College of Medicine, Daegu, Korea
}

\begin{abstract}
There has been a significant increase in the number of multiple pregnancies that are associated with a high risk of preterm delivery among Korean women. However, to date, delayed-interval delivery in women with multiple pregnancy is rare. We report a case of delayed-interval delivery performed 128 days after the vaginal delivery of the first fetus in a dichorionic diamniotic twin pregnancy. The patient presented with vaginal leakage of amniotic fluid at 16 weeks of gestation and was diagnosed with a preterm premature rupture of membranes. Three days later, the first twin was delivered, but the neonate died soon after. The second twin remained in utero, and we decided to retain the fetus in utero to reduce the morbidity and mortality associated with a preterm birth. The patient was managed with antibiotics and tocolytics. Cervical cerclage was not performed. The second twin was delivered vaginally at 34 weeks and 5 days of gestation, 128 days after the delivery of the first-born fetus. This neonate was healthy and showed normal development during the 1-year follow-up period. Based on our experience with this case, we propose that delayed-interval delivery may improve perinatal survival and decrease morbidity in the second neonate in highly selected cases.
\end{abstract}

Keywords: Delayed-interval delivery; Multiple pregnancy; Twin pregnancy; Premature birth

\section{INTRODUCTION}

Although the total number of deliveries has been steadily decreasing every year in Korea, the number of multiple pregnancies has increased dramatically in the past 20 years. The number of twin births increased by 47\% from 5,146 in 2000 to 7,573 in 2016 [1]. Multiple pregnancy is associated with higher risks of various maternal and fetal complications, than a singleton pregnancy, these include preterm birth, spontaneous abortion, low-birth-weight infant, and congenital malformations. In particular, preterm delivery is the main cause

Received: May 11, 2018, Revised: June 2, 2018 Accepted: June 2, 2018

Corresponding Author: Yu-Jin Koo, Department of Obstetrics and Gynecology, Yeungnam University College of Medicine, 170, Hyeonchung-ro, Nam-gu, Daegu 42415, Korea Tel: +82-53-620-3433, Fax: +82-53-654-0676

E-mail: yujinkoo@yu.ac.kr of the increased maternal morbidity and mortality in multiple pregnancy, therefore, it is important to make the best effort to prevent a preterm delivery. With this in mind, some researchers have recently tried to delay the subsequent delivery of the retained fetus after the preterm delivery of the firstborn fetus; this was introduced as delayed-interval delivery or asynchronous delivery in several literature. There is no clear definition of delayed-interval delivery, the gestational age and the interval has varied widely based on the study. Nevertheless, a delayed-interval delivery is generally defined as an active attempt (tocolysis and/or cerclage placement) to increase latency between the delivery of the first fetus and subsequent fetuses in the second trimester [2]. In a report published in 2004, the occurrence rate of delayed-interval delivery was only 0.14 per 1,000 births in the United States [2]. In most of the cases in the literature that was published to date, the interval periods were short, within 1 month. Furthermore, few cases of delayed-interval delivery have been reported in

Copyright (C) 2018 Yeungnam University College of Medicine

This is an Open Access article distributed under the terms of the Creative Commons Attribution Non-Commercial License (http://creativecommons.org/licenses/by-nc/4.0/) which permits unrestricted non-commercial use, distribution, and reproduction in any medium, provided the original work is properly cited. 
Korea. Hence, we report a successful case of delayed-interval delivery that occurred at 34 weeks and 5 days of gestation, 128 days after the vaginal delivery of the first fetus in a twin pregnancy.

\section{CASE}

Patient: Female, 29 years old

Presenting complaint: A sudden gush of clear fluid from the vagina

\section{Obstetric history: $0-0-0-0$}

History of presenting complaint: A woman with a twin pregnancy at 16 weeks of gestation, visited a local clinic because of vaginal leakage of amniotic fluid that occurred 3 hours prior to presentation, while sleeping. She was diagnosed with a preterm premature rupture of membrane and was referred to our hospital after learning that it was likely no longer possible to maintain the pregnancy.

Past history: There was no medical history of chronic diseases. She conceived the dichorionic diamniotic (DCDA) twins naturally and was followed up regularly at an obstetric clinic from 5 weeks of gestation. Except for the history of threatened abortion at 6 weeks of gestation, there was no abnormal finding in her antenatal course. She was taking oral folic acid and iron supplements.

Family history: Her father and mother had hypertension.
Physical examination: At presentation, the patient showed the followings: height $160 \mathrm{~cm}$, body weight $72 \mathrm{~kg}$, body mass index $28.1 \mathrm{~kg} / \mathrm{m}^{2}$, blood pressure $130 / 80 \mathrm{mmHg}$, pulse rate 80 beats/min, and body temperature $37.0^{\circ} \mathrm{C}$. On speculum examination, the cervix was closed but there was a small volume of clear fluid in the vagina, which tested positive in the nitrazine test.

Laboratory findings: Blood test showed increased levels of white blood cell (WBC) $11,790 / \mathrm{mm}^{3}$, neutrophil $82.8 \%$, and C-reactive protein (CRP) $0.52 \mathrm{mg} / \mathrm{dL}$ (range, $<0.5 \mathrm{mg} / \mathrm{dL}$ ). The hemoglobin level decreased to $9.3 \mathrm{~g} / \mathrm{dL}$ and the platelet count was normal $\left(264,000 / \mathrm{mm}^{3}\right)$. The results of the liver function test, renal function test, and urine analysis were normal. Tests for congenital intrauterine infection and sexually transmitted disease were not performed.

Imaging findings: Ultrasonography showed the first fetus with a breech presentation, a heart rate of 140 beats/min, was nearly anhydramnios with a maximal vertical pocket (MVP) of $0.7 \mathrm{~cm}$, and hyperflexion of the body, trunk, and extremities. The second fetus had a breech presentation, heart rate of 142 beats $/ \mathrm{min}$, and MVP of $4.1 \mathrm{~cm}$. The cervical length was $2.7 \mathrm{~cm}$ with Y-shaped funneling (Fig. 1A).

Management and clinical progress: Since she was hospitalized, absolute bed rest was recommended and intravenous antibiotics (ceftezole, $1 \mathrm{~g}$ ) were administered twice daily. Although uterine contraction was not found on electronic fetal
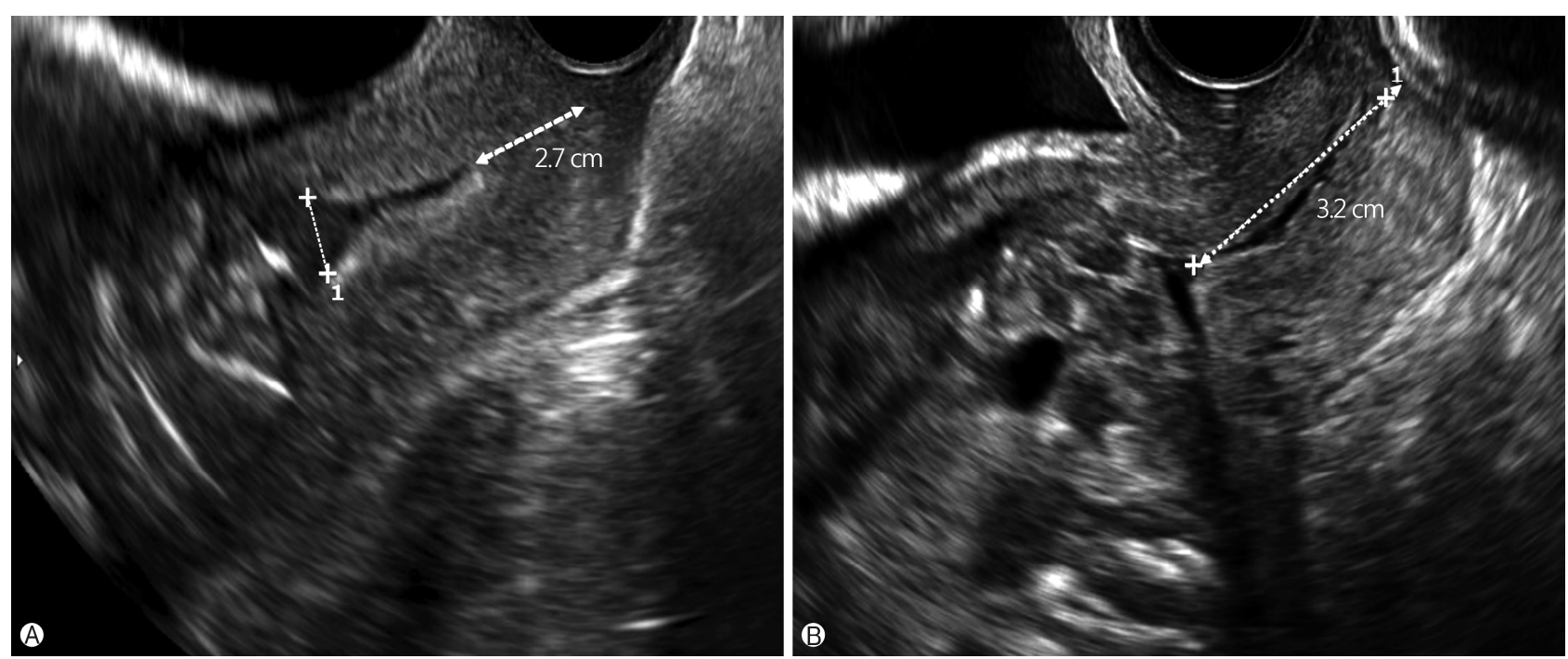

Fig. 1. Transvaginal ultrasonographic examination shows images of the cervix. The functional length of the cervix was observed to be $2.7 \mathrm{~cm}$ with Y-shape funneling at the time of the patient's visit to the emergency room at 16 weeks of gestation (A). The cervical length was observed to have normalized to $3.2 \mathrm{~cm}$ without funneling 8 days after the delivery of the first-born fetus (B). 
monitoring (EFM), she complained of intermittent lower abdominal pain with continuous leakage of amniotic fluid. Three days after hospital admission (16 weeks and 3 days of gestation), the first fetus was delivered but the neonate died soon after. The dead fetus was male, weighed $100 \mathrm{~g}$, and was without gross malformation. The second twin remained in utero and we decided to retain the fetus in utero to reduce the morbidity and mortality associated with a preterm birth. The placenta of the first-born fetus remained in utero. The umbilical cord was tied with silk \#2-0 and cut at a level close to the cervix. On transvaginal ultrasonography, the remaining fetus had active movements, fetal heart rate was 160 beats $/ \mathrm{min}$, and MVP was $3.5 \mathrm{~cm}$. After the delivery of the first fetus, since the cervical length was $4.2 \mathrm{~cm}$ and without funneling, cervical cerclage was not performed. The patient was managed with oral doses of sulindac at $200 \mathrm{mg}$, twice a day for 5 days, in addition to the ceftezole. A vaginal suppository of povidone-iodine was inserted daily, oral iron and laxatives were also used. To prevent a thromboembolic event, an elastic compressive stocking was applied.

One day after the delivery of the first fetus, the patient had intermittent abdominal pain; irregular uterine contractions of $10-15 \mathrm{mmHg}$ intensity were found, based on the EFM. Blood test showed CRP of $0.85 \mathrm{mg} / \mathrm{dL}$, D-dimer of $1.36 \mu \mathrm{g} / \mathrm{dL}$ (range, $<0.5 \mu \mathrm{g} / \mathrm{dL}$ ), and fibrinogen of $485 \mathrm{mg} / \mathrm{dL}$ (range, 200$400 \mathrm{mg} / \mathrm{dL}$ ). Fortunately, the abdominal pain disappeared after tocolytic therapy using intravenous ritodrine was started. At a gestational age of 17 weeks and 4 days, she complained of vaginal spotting but there was no active bleeding on vaginal speculum examination, the fetal heart rate and movement were normal on ultrasonography, the cervical length was 3.2 $\mathrm{cm}$ (Fig. 1B), and the WBC and CRP levels in the blood were normal, so we continued the ceftezole and ritodrine use. The patient's condition became stable and she was discharged from the hospital at 25 weeks of gestation with a plan of follow-up every 2 weeks.

At 34 weeks and 4 days of gestation, she presented with leakage of amniotic fluid and labor pain. On examination, the fetus had a cephalic presentation, and the cervix was dilated to $2 \mathrm{~cm}$. The second twin was delivered vaginally at 34 weeks and 5 days of gestation, 128 days after the delivery of the first-born fetus. The neonate was male, weighed 2,370 g, and was healthy with Apgar scores of 9 at 1 minute and 10 at 5 minutes. The placenta was grossly unremarkable, the placental portion of the first fetus was not definitely distinguishable. Blood $\mathrm{O}_{2}$ saturation of the neonate was $97-100 \%$ on $\mathrm{O}_{2}$ supply $0.5 \mathrm{~L} / \mathrm{min}$ via nasal prongs alone and there was no evidence of any infection or hemorrhage. The neonate was discharged on the 15th day after birth. Because brain sonography showed suspicious findings of periventricular leukomalacia on the 6th day after birth, brain magnetic resonance imaging was performed but the results were normal. An atrial septal defect, $2 \mathrm{~mm}$ in size was detected on cardiac sonography on the 13th day after birth, however, a follow-up examination was normal. The neonate was healthy and had a normal development during the 1-year follow-up period.

\section{DISCUSSION}

Since Carson first reported a case of delayed-interval delivery with 44 days of interval in a woman with twin pregnancy in 1880 [3], there has been a worldwide increase in studies of delayed-interval delivery in multiple pregnancy. The general view is that the success rate of delayed-interval delivery is improving according to the advancement of medicine and the perinatal outcome is good in selected patients $[4,5]$. Wittmann et al. reported that the survival rate of retained siblings was as high as $84 \%$ in 21 cases of delayed-interval delivery in their literature review [6], and Kalchbrenner et al. reported a survival rate of 78\% [7]. In addition, Zhang et al. compared the perinatal outcomes between the delayed and non-delayed twins [4]. For the delayed twins, they identified the pregnancies in which the first twin was delivered between 17 and 29 weeks of gestation and the second twin was delivered 2 or more days later. The result showed a delayed delivery was associated with improved infant survival to 1 year of age (56\% vs. $24 \%, p<0.001$ ) and a higher birth weight in the second twin. In contrast, reviewing the 14 cases of delayedinterval delivery performed at two tertiary care centers over 12 years, Livingston et al. showed that the survival rate of retained siblings was only $37 \%$ and most fetal survivors had significant damage from preterm birth [2]. Therefore, carefully selecting the patient and strict management can point to the success and hence its importance cannot be overemphasized.

There is currently no established guideline on the target indication and the ideal interval for a delayed-interval delivery. In 2005, Oyelese et al. analyzed perinatal outcomes 
of a delayed-interval delivery in which the first twin was delivered vaginally at 22 to 28 weeks of gestation and the second twin was delivered at least a week after the first [8]. They found that delayed delivery of the second twin was associated with reduced perinatal and infant mortality when the first twin was delivered at 22 to 23 weeks of gestation and the delivery interval was $\leq 3$ weeks. Conversely, delayed delivery of the second twin when either the first was delivered at $\geq 24$ weeks or the delivery interval was $\geq 4$ weeks had no benefit with regard to mortality. Their study was a retrospective population-based study and was the largest study regarding delayed-interval delivery published to date. However, because the study population was limited to 22-28 weeks of gestation, their study result provides little information about neonatal outcomes in cases where the first fetus is delivered in the early second trimester, like in the present case.

In Korea, there have been several studies regarding delayedinterval delivery. The largest study was reported in 2011 and it reviewed nine cases of twin or triplet pregnancies [9]. The authors concluded that delayed-interval delivery could decrease the incidence of small for gestational age of the remaining fetuses and that prolonged gestation would not be harmful to those fetuses after birth. However, the delay interval was short with a range of 0.4-30 days and it was within 2 weeks in seven of nine women.

Not only the effect on the fetus but also the effect on the mother was different according to the studies. Some reported that severe maternal complication was not found in delayed pregnancies [10,11], however, Arabin and van Eyck stated that the frequent maternal complications were chorioamnionitis (22\%), postpartum hemorrhage (10\%), retained placenta (10\%), placental abruption (6\%), and sepsis (2\%) [12]. Such severe complications can be a serious threat to both the fetus and mother. Therefore, clinicians should be aware of the advantages and disadvantages of delayed-interval delivery and closely monitor the maternal and fetal conditions through regular tests for infection and fetal surveillance during the delay period.

Although the guidelines for extending the delay interval while improving the perinatal outcomes have not been clarified yet, aggressive tocolysis and prophylactic antibiotics tend to be the standard management [4]. In addition, recent studies suggest that cervical cerclage immediately after first delivery may prolong the duration of delay [13-15]. According to the study by Farkouh et al., the mean of the delay interval was significantly longer in patients with cerclage placement than in patients who had undergone removal of the previous cerclage at the time of the first delivery ( 40 days vs. 11 days; $p=$ 0.004) [15]. However, the effect of cerclage on delay interval is still under debate, and several authors have published cases of long delay interval without performing cerclage [16]. In the present case, we did not perform cerclage because the first-born fetus was delivered early, weighed only $100 \mathrm{~g}$, and the cervical length was $4.2 \mathrm{~cm}$.

Possible contributory factors to such a long latency include the following: most importantly, the first delivery occurred early at 16 weeks and 3 days of gestation; it is broadly accepted that the delay interval can be successfully prolonged and perinatal outcomes are excellent if the first delivery occurs as early as possible $[8,15]$. Secondly, our case was a DCDA twin. Chorionicity has a vital role in the incidence of obstetric complications in multiple pregnancy. For example, a DCDA twin is associated with a lower incidence of most complications including preterm birth than a monochorionic twin. In addition, it has been suggested that chorionicity is also a prognostic factor in delayed-interval delivery [15], however, further research in this regard is needed. Thirdly, we expect that the absolute bed rest was helpful for the successful delay. Although no study has investigated whether bed rest is effective in delayed-interval delivery of multiple pregnancy, there is a general agreement that bed rest has no significant effect on prevention of preterm delivery in singleton pregnancy [17]. Nevertheless, many researchers consider bed rest important and strongly recommend it to the mother when attempting to delay the delivery $[11,15]$. However, since absolute bed rest increases the risk of maternal constipation, weight gain, and thromboembolic events, measures to prevent these risks should be included in the management of the patient. Lastly but important, we believe that the strict care of perineal hygiene and daily use of vaginal povidone suppository was helpful. Given the fact that ascending infection from the genital tract can cause serious complications such as chorioamnionitis and sepsis [18], management of a successful delayed-interval delivery centers on the care of genital infection.

In the present study, we report a case of delayed-interval delivery that occurred 128 days after the vaginal delivery of the first fetus in a twin pregnancy, which is the case with the longest interval period published in Korea. We propose 
that delayed-interval delivery may improve perinatal survival and decrease morbidity in the second neonate in highly selected cases. Further studies are required to clarify the indication as well as the standard management for delayed-interval delivery. The effect of progesterone therapy, which is used to prevent preterm birth in a singleton pregnancy, is also worthy of study. We hope that several more cases with a long delay interval are reported to further elucidate the delay interval-dependent maternal and fetal outcomes.

\section{CONFLICT OF INTEREST}

No potential conflict of interest relevant to this article were reported.

\section{ORCID}

Yu-Jin Koo, https://orcid.org/0000-0002-5114-8000

\section{REFERENCES}

1. Korean Statistical Information Service. Birth and death statistics twin birth [Internet]. Daejeon: KOSIS; 2016 [cited 2018 May 5]. http://kosis.kr/index/index.do

2. Livingston JC, Livingston LW, Ramsey R, Sibai BM. Secondtrimester asynchronous multifetal delivery results in poor perinatal outcome. Obstet Gynecol 2004;103:77-81.

3. Carson JL. Twins born with an interval of forty-four days. Br Med J 1880;1:242.

4. Zhang J, Hamilton B, Martin J, Trumble A. Delayed interval delivery and infant survival: a population-based study. Am J Obstet Gynecol 2004;191:470-6.

5. Fayad S, Bongain A, Holhfeld P, Janky E, Durand-Réville $\mathrm{M}$, Ejnes L, et al. Delayed delivery of second twin: a multicentre study of 35 cases. Eur J Obstet Gynecol Reprod Biol 2003; 109:16-20.

6. Wittmann BK, Farquharson D, Wong GP, Baldwin V, Wadsworth LD, Elit L. Delayed delivery of second twin: report of four cases and review of the literature. Obstet Gynecol 1992;79:260-3.

7. Kalchbrenner MA, Weisenborn EJ, Chyu JK, Kaufman HK, Losure TA. Delayed delivery of multiple gestations: maternal and neonatal outcomes. Am J Obstet Gynecol 1998;179: 1145-9.

8. Oyelese Y, Ananth CV, Smulian JC, Vintzileos AM. Delayed interval delivery in twin pregnancies in the United States: Impact on perinatal mortality and morbidity. Am J Obstet Gynecol 2005;192:439-44.

9. Lee EH, Sohn JA, Lee JY, Choi EJ, Lee JA, Choi CW, et al. The impact of delayed interval delivery on neonatal mortality and morbidity. J Korean Soc Neonatol 2011;18:111-6. Korean.

10. Rosbergen M, Vogt HP, Baerts W, van Eyck J, Arabin B, van Nimwegen-Hamberg JM, et al. Long-term and short-term outcome after delayed-interval delivery in multi-fetal pregnancies. Eur J Obstet Gynecol Reprod Biol 2005;122:66-72.

11. van Doorn HC, van Wezel-Meijler G, van Geijn HP, Dekker GA. Delayed interval delivery in multiple pregnancies. Is optimism justified? Acta Obstet Gynecol Scand 1999;78:710-5.

12. Arabin B, van Eyck J. Delayed-interval delivery in twin and triplet pregnancies: 17 years of experience in 1 perinatal center. Am J Obstet Gynecol 2009;200:154.e1-8.

13. Doger E, Cakiroglu Y, Ceylan Y, Kole E, Ozkan S, Caliskan E. Obstetric and neonatal outcomes of delayed interval delivery in cerclage and non-cerclage cases: an analysis of $20 \mathrm{mul}-$ tiple pregnancies. J Obstet Gynaecol Res 2014;40:1853-61.

14. Zhang J, Johnson CD, Hoffman M. Cervical cerclage in delayed interval delivery in a multifetal pregnancy: a review of seven case series. Eur J Obstet Gynecol Reprod Biol 2003; 108:126-30.

15. Farkou LJ, Sabin ED, Heyborne KD, Lindsay LG, Porreco RP. Delayed-interval delivery: extended series from a single maternal-fetal medicine practice. Am J Obstet Gynecol 2000; 183:1499-503.

16. Ahn HS. A successful delayed-interval delivery without cerclage operation after one fetal delivery in a case of twin pregnancy. Korean J Perinatol 2009;20:395-400.

17. Sosa C, Althabe F, Belizán J, Bergel E. Bed rest in singleton pregnancies for preventing preterm birth. Cochrane Database Syst Rev 2004;(1):CD003581.

18. Trivedi AN, Gillett WR. The retained twin/triplet following a preterm delivery--an analysis of the literature. Aust $\mathrm{N} \mathrm{Z}$ J Obstet Gynaecol 1998;38:461-5. 